\title{
Дистанционное образование: методические аспекты и практический опыт организации на факультете географии, геоэкологии и туризма
}

\author{
С. А. Куролап $\bowtie$ \\ Воронежский государственный университет, Российская Федераџия \\ (394018, г. Воронеж, Университетская площадь, 1)
}

\begin{abstract}
Аннотация: Цель - анализ современных особенностей и практических результатов применения дистанционных образовательных технологий (ДОТ) в системе подготовки выпускников эколого-географических направлений. Материалы и методы. Системный анализ особенностей применения дистанционных образовательных технологий на примере факультета географии, геоэкологи и туризма в 2020 году, выявление положительных и отрицательных сторон, описание методических особенностей эффективного обучения с использованием ДОТ. Результаты и обсуждение. Положительные результаты применения цифровых технологий образования показаны на примере внедрения электронных онлайн-курсов, дополнительных программ повышения квалификации, расширения информационно-коммуникативных технологий взаимодействия в системе «студент-преподаватель». Полученный положительный опыт применения ДОТ служит основой дальнейшего развития цифровых технологий обучения в системе университетского образования. Заключение. Внедрение дистанционного образования имеет как положительные результаты, так и проблемные моменты. Но положительные эффекты предпочтительнее, что позволяет активнее продвигать дистанционные технологии в образовательный процесс. Предпочтение следует отдавать двум образовательным моделям: 1) полный переход на дистанционное обучение при организации повышения квалификации и профессиональной переподготовки; 2) частичное использование дистанционных образовательных технологий.
\end{abstract}

Ключевые слова: цифровизация образования, дистанционные технологии, онлайн-курсы, инновационные подходы в педагогике.

Для цитирования: Куролап С.А. Дистанционное образование: методические аспекты и практический опыт организации на факультете географии, геоэкологии и туризма // Вестник Воронежского государственного университета. Серия География. Геоэкология, 2020, № 4, с. 79-84. DOI: https://doi.org/10.17308/geo.2020.4/3068

\section{ВВЕДЕНИЕ}

В современных условиях отечественное образование проходит непростые этапы модернизации, в том числе широкую цифровизацию во всех сфеpax, экстренный переход на дистанционные образовательные технологии (ДОТ) в условиях пандемии $[1,2]$. Этот переход несет в себе как положительные, так и отрицательные, негативные проявления, которые рассмотрим на примере использования ДОТ в учебном процессе Воронежского государственного университета на факультете гео- графии, геоэкологии и туризма в течение мартаоктября 2020года.

В процессе активного вовлечения студентов и преподавателей в дистанционный формат обучения используются различные электронные платформы (Moodle, ZOOM, Skype и др.). Существенно вырос интерес к цифровизации всех этапов образования. На повестку дня ставится вопрос: что это - «прорывные технологии», способные существенно повысить эффективность обучения или вынужденная мера реализации образовательного

() Куролап С.А., 2020

\уролап Семен Александрович, e-mail: skurolap@mail.ru Контент доступен под лицензией Creative Commons Attribution 4.0 License. 
процесса по принципу «лучше, чем ничего»? Важнейшей задачей данного периода является поэтапная адаптация учебного процесса к современным условиям таким образом, чтобы эффективность обучения в целом возрастала, а не утрачивалась.

\section{МАТЕРИАЛЫ И МЕТОДЫ ИССЛЕДОВАНИЯ}

Основная технология дистанционного обучения - это мультимедийные лекции, а также размещение в электронной среде материалов к лекциям, практическим и лабораторным занятиям (тексты, презентации, видеоконференции), проведение автоматизированной аттестации (тестовый контроль, решение ситуационных задач, написание эссе, рефератов, сдача экзаменационных испытаний).

Как показывает системный анализ этих процессов, к положительным аспектам такого формата обучения можно отнести следующее.

1. Возможность для студента и преподавателя более обстоятельно осмыслить материал изучаемой дисциплины за счет неоднократного «возврата назад» к материалу курса, возможность исправления, дополнения, усовершенствования изложения опорных понятий, закономерностей, т.е. это элемент саморазвития и дополнительного взаимодействия «студент-преподаватель». В таком случае студент может вникнуть в материал более спокойно в домашней обстановке выполнения самостоятельных заданий. Например, опыт решения задач в области математической статистики показывает, что при аудиторных занятиях самостоятельно, без дополнительных объяснений со стороны педагога могли решить задачи около 50-60\% студентов, то в условия применения дистанционных образовательных технологий их число выросло до $70-75 \%$.

2. Использование информационных технологий позволяет студенту в целом дисциплинировать мышление, отрабатывать навыки бесконтактного взаимодействия с преподавателем, самостоятельно мыслить, адаптируясь к новым реалиям.

Из негативных, проблемных, моментов необходимо отметить следующее.

1. Неготовность значительной части преподавателей к проведению учебного процесса на электронной платформе из-за недостаточной технической оснащенности, а также из-за незнания современных компьютерных технологий. Если для преподавателей до 40 лет и студентов они не вызывают каких-либо преград в освоении материала, то для профессорско-преподавательского состава более старшего возраста, это становится иногда заметным «тормозом» в организации учебного процесса, к формату которого нужна адаптация. Одной из существенных проблем дистанционного образования стала недостаточная подготовка преподавателей и студентов для установки платформ Интернет-ресурсов /у кого-то стационарный компьютер, у кого-то только смартфон, планшет/, но это проблема временная.

2. Трудности в проведении экспериментальных, практических работ и их транслировании для студентов. Так, можно посмотреть и понять технологию работы с лабораторным оборудованием, но освоить практические навыки в дистанционном формате невозможно, необходима контактная работа с преподавателем и выполнение работы «своими руками». Именно поэтому ряд лабораторных занятий по таким дисциплинам как «геохимия окружающей среды», «аналитические методы исследований» для студентов-геоэкологов были перенесены с весеннего семестра обучения на осенний семестр 2020 года.

3. Существенно страдает психолого-педагогический элемент обучения, исчезает возможность реализации воспитательного момента в образовании, нет зрительного контакта, речевого взаимодействия в системе «студент-преподаватель», не хватает эмоционально окрашенной личностной оценки результата работы студента со стороны преподавателя, что нередко ведет к падению мотивации, психологических стимулов в образовании. Наконец, известно, что часто мотивацией для студента является «работа на результат», честные конкурентные отношения со сверстниками, стремление выделиться из группы однокурсников, показать себя знающим и уверенным в решении тех или иных учебных задач, что существенно «снижено» в условиях дистанционного обучения.

Таким образом, в организации учебного процесса с применением ДОТ многое уходит в сферу самоорганизации студента и преподавателя, часто не давая прямого ответа о бесспорной пользе или просчетах такого формата обучения. В конечном итоге, все зависит от мастерства преподавателя и умения студента адаптироваться к новому формату образования, что в полной мере отвечает современным задачам практико-ориентированного обучения [4]. Значимым показателем успешности экстренного перехода на дистанционный формат обучения является применение смешанного обучения (например, аудиторные занятия и онлайнлекции). 
Дистанционное образование: методические аспекты и практический опыт организации на факультете географии, геоэкологии и туризма

\section{РЕЗУЛЬТАТЫ И ОБСУЖДЕНИЕ}

В течение весны-осени 2020 года практически все учебные дисциплины и практики факультета географии, геоэкологии и туризма переведены на электронный формат обучения. Среди хороших примеров оформления электронных курсов можно отметить курс «Экологическое проектирование и экспертиза» (https://edu.vsu.ru/course/ view.php?id=3146), предназначенный для изучения студентами-бакалаврами направления «Экология и природопользование» /4 курс, 7 семестр, разработчик - профессор О.В. Клепиков/. Данная дисциплина рассматривает нормативно-правовые акты в области инженерно-экологического проектирования, систему экологического нормирования, методики расчета и порядок подготовки проектов предельно допустимых выбросов загрязняющих веществ в атмосферный воздух (ПДВ), нормативно-допустимых сбросов сточных вод в водные объекты (НДС), санитарно-защитных зон предприятий (С33), нормативов образования отходов и лимитов на их размещение. Методические приемы, использованные при составлении курса - технология проведения онлайн-лекций, презентации по опорным темам, практические ситуационные задачи по основным темам, компьютерные тесты для проведения промежуточной аттестации. Интересные решения, авторские мультимедийные лекции, широкое применением интерактивных форм обучения затронуло и другие направления в сфере «Природопользования», «Географии» и «Туризма». Так, целый ряд курсов в области опасных явлений погоды, аэрокосмических методов исследований, физической и экономической географии, в том числе учебных практик, ориентирован на цифровизацию; в аналогичном направлении происходит развитие образования в сфере туризма, которое опирается на инновационные методы преподавания (мультимедийные лекции, проектный метод, мозговой штурм, деловые игры и др.) в контексте все более расширяющегося интерактивного и цифрового обучения [3].

К положительным аспектам внедрения ДОТ в учебный процесс можно отнести возможность приобщения к крупным образовательным площадкам, в частности, к национальной платформе открытого образования. Назовем только два курса, успешно апробированных студентами и преподавателями факультета в течение апреля-мая 2020 г.

Дистанционный курс «Информационные технологии природоохранной деятельности» (https://openedu.ru/course/spbstu/ITEA), разработ- чик - Санкт-Петербургский политехнический университет Петра Великого совместно с СПбГЭТУ «ЛЭТИ», при поддержке Северо-Западного регионального центра компетенций в области онлайнобучения; автор - А. С. Ковалевская. Курс посвящен профессиональной подготовке специалистов в сфере инженерной защиты окружающей среды и организации природоохранной деятельности на предприятии в условиях широкого внедрения цифровых технологий экологического мониторинга и контроля. Описаны основные методы и принципы работы с экологической информацией, в том числе вопросы организации сбора, обработки, хранения, передачи и представления экологической информации. Отдельное внимание уделяется вопросам проектирования и использования в работе эколога-практика электронных экологических баз данных. Изложены основы компьютерного моделирования загрязнения атмосферы, основные методические принципы расчета загрязнения воздушного бассейна. Рассмотрены аспекты применения современных программных средств для автоматизированного экологического контроля в организации.

Дистанционный курс «Экология» (https:// openedu.ru/course/eltech/ECO), разработчик Санкт-Петербургский государственный электротехнический университет «ЛЭТИ» им. В. И. Ульянова (Ленина); авторы - О. В. Смолова и А. С. Ковалевская. Целью изучения данной дисциплины является получение фундаментальных знаний о современных экологических проблемах природного и антропогенного характера, а также приобретение обучающимися прикладных знаний о последствиях своей профессиональной деятельности в области охраны окружающей среды. В материалах курса хорошо изложены основы общей экологии, учение В.И. Вернадского о биосфере и его развитие в настоящее время, рассмотрены закономерности функционирования природных и антропогенно измененных экологических систем, вопросы техногенного загрязнения среды обитания, основные экологические проблемы и пути их решения. В программу курса включены оригинальные обучающие видео об экологической деятельности различных организаций города Санкт-Петербурга (экологическое просвещение жителей Детский экологический центр г. Санкт-Петербурга; мониторинг окружающей среды - ГУП СФ «Минерал»; биоиндикационные исследования городской среды - Санкт-Петербургский научно-исследовательский центр экологической безопаснос- 
ти РАН; управление в области охраны окружающей среды - Комитет по природопользованию, охране окружающей среды и экологической безопасности г. Санкт-Петербурга; вопросы загрязнения атмосферного воздуха - СПбГЭТУ «ЛЭТИ»; проблемы образования и обезвреживания отходов ЗАО «Турмалин», Учебно-методический центр «Утилизация и обезвреживание отходов» СПбГЭТУ «ЛЭТИ»).

Оценка качества освоения программы дисциплины «Экология» осуществляется с помощью текущего контроля успеваемости (тестирование), выполнения нескольких практических заданий и итогового контроля. Результаты тестирований и выполненных заданий оцениваются по рейтинговой системе.

Одним из новых элементов образования становится и система повышения квалификации преподавателей, которая в значительной степени становится дистанционной. Так, еще до начала пандемии в России в феврале 2020 года на факультете была открыта по заказу Белгородского государственного научно-исследовательского университета (НИУ «БелГУ») новая междисциплинарная программа повышения квалификации работников образования «Современные тенденции в реализации учебных программ в области наук о Земле и IT- и ГИС-технологии» /объем - 72 часа; руководитель - профессор С. А. Куролап, ответственные исполнители - доценты Ю. А. Нестеров, С. А. Епринцев, А. С. Горбунов, старший преподаватель - Д. В. Сарычев/. Положительные итоги ее разработки подтверждены успешной реализацией программы в течение последующих месяцев, исключительно в дистанционном режиме. Так, за период с середины апреля до середины июня было обучено 80 слушателей факультета горного дела и природопользования НИУ «БелГУ» и 10 слушателей факультета. Целью освоения дополнительной образовательной программы является актуализация знаний и приобретение слушателями новых знаний в области современных тенденций преподавания в области наук о Земле, а также практических навыков применения современных IT- и ГИС-технологий в преподавании учебных дисциплин. Содержательная часть образовательной программы включает основы цифровизации системы естественно-научного преподавания, особенности формирования профессиональных компетенций, достигаемых с использованием современных информационных технологий, «сквозной» подход в области внедрения IT- и ГИС-технологий в учебный процесс, способы повышения эффективности образовательного процесса с использованием цифровых технологий.

Значительное место в плане данной программы повышения квалификации уделено современным направлениям развития геоинформационного картографирования, возможностям использования результатов геоинформационного картографирования в учебном процессе направлений подготовки «География» и «Экология и природопользование», вопросам применения результатов дистанционного зондирования для решения учебно-научных задач, технологиям создания и применения геоинформационных ресурсов для решения задач экологического проектирования и экологического мониторинга на базе открытых геоинформационных ресурсов (QGIS, GRASS, SAGA, GvSIG, ILWIS).

Помимо указанных мероприятий в период дистанционной работы на факультете географии, геоэкологии и туризма успешно апробированы открытые онлайн лекции, научные конференции /например, круглый стол памяти профессора Ю. В. Поросенкова, инициированный кафедрой социальноэкономической географии и регионоведения/, школьный «географический чемпионат» на базе Центра дополнительного образования школьников «ОРИОН», при участии Воронежского регионального центра развития школьного географического образования /куратор от факультета - старший преподаватель В.В. Свиридов/.

\section{ЗАКЛЮЧЕНИЕ}

Широкое внедрение дистанционных образовательных технологий в российское образование имеет как положительные, так и проблемные моменты. Положительные эффекты ожидаются сильнее, что является дальнейшей основой активного продвижения и развития таких технологий. При реализации образовательных программ с применением электронного обучения, дистанционных образовательных технологий в университете могут быть применены следующие модели: 1) полностью дистанционное обучение (повышение квалификации, профессиональная переподготовка) обучаемого (слушателя); 2) частичное использование дистанционных образовательных технологий, позволяющих организовать дистанционное обучение (повышение квалификации, профессиональная переподготовка) обучаемого (слушателя) в смешанном формате, причем, в настоящий момент это наиболее адекватная современным реалиям форма организации учебного процесса. 
Дистанционное образование: методические аспекты и практический опыт организащии на факультете географии, геоэкологии и туризма

Применение ДОТ в университетском образовании требует также развития нормативной базы (регламенты о порядке и особенностях реализации образовательных программ с использованием электронного обучения, дистанционных образовательных технологий); специализированного материально-технического обеспечения (создание электронных информационных ресурсов, телекоммуникационных технологий, соответствующих технологических средств); кадрового обеспечения (желательно наличие у педагогических работников соответствующего основного или дополнительного профессионального образования в области компьютерных технологий).

Очевидно, что применение дистанционных технологий уже прочно обосновалось в отечественном образовании, что может стать еще одним шагом в повышении эффективности образования в целом.

\section{СПИСОК ЛИТЕРАТУРЫ}

1. Сафуанов Р.М., Лехмус М.Ю., Колганов Е.А. Цифровизация системы образования // Вестник УГНТУ. Наука, образование, экономика. Серия Экономика, 2019, № 2(28), с. 116-121.

2. Танцюра Т. А. Аспекты дистанционного обучения в современных условиях // Мир науки, культуры, образования, 2020, №2(81), с. 355-358.

3. Тимошенко Д.С. Инновационные подходы и технологии в туристской педагогике // Вестник Boронежского государственного университета. Серия География. Геоэкология, 2020, № 1, с. 115-123. DOI: https://doi.org/10.17308/geo.2020.1/2669

4. Федотов В. И., Куролап С. А. Современная модель университетского экологического образования // Becтник Воронежского государственного университета. Серия Проблемы высшего образования, 2017, №3, c. $14-18$.

Конфликт интересов: Автор декларирует отсутствие явных и потенциальных конфликтов интересов, связанных с публикацией настоящей статьи.

Поступила в редакцию 02.11.2020

Принята к публикаичи 20.11.2020

\title{
METHODS OF TEACHING
}

\section{Distance Education: Methodological Aspects and Practical Experience of Organization in the Faculty of Geography, Geoecology and Tourism}

\author{
S.A. Kurolap ${ }^{凶}$ \\ Voronezh State University, Russian Federation \\ (1, Universitetskaya sq., Voronezh, 394018)
}

\begin{abstract}
Purpose: analyze modern features and practical results of the use of distance learning technologies (DOT) in the system of training graduates of environmental and geographical areas. Materials and methods: a systematic analysis of the features of the use of distance educational technologies on the example of the Faculty of Geography, Geoecology and Tourism in 2020, identification of positive and negative sides, formulation of methodological principles of effective teaching using DOT. Results and discussion: The positive results of the use of digital education technologies are shown on the example of the introduction of electronic online courses, additional training programs, the expansion of information and communication technologies of interaction in the "student-teacher" system. The obtained positive experience of using DOT serves as the basis for the further development of digital learning technologies in the university education system. Conclusion. The introduction of distance education has both positive results and problematic points. But positive effects are preferable, which makes it possible to actively promote distance technologies in the
\end{abstract}

(C) Kurolap S. A., 2020

\Semen A. Kurolap, e-mail: skurolap@mail.ru

(c) (i) The content is available under Creative Commons Attribution 4.0 License. 


\section{S.A. Kurolap}

educational process. Preference should be given to two educational models: 1) full transition to distance learning with organizing advanced training and professional retraining; 2) partial use of distance learning technologies.

Key words: digitalization of education, distance technologies, online courses, innovative approaches in pedagogy.

For citation: Kurolap S. A. Distance education: methodological aspects and practical experience of organization in the Faculty of Geography, Geoecology and Tourism. Vestnik Voronezskogo gosudarstvennogo universiteta. Seria Geografia. Geoekologia, 2020, No. 4, pp. 79-84. (In Russ.) DOI: https://doi.org/10.17308/geo.2020.4/3068

\section{REFERENCES}

1. Safuanov R. M., Lekhmus M. YU., Kolganov E. A. Cifrovizaciya sistemy obrazovaniya [Digitalization of the education system]. Vestnik UGNTU. Nauka, obrazovanie, ekonomika. Seriya Ekonomika, 2019, no. (28), pp. 116-121. (In Russ.)

2. Tancyura T. A. Aspekty distancionnogo obucheniya v sovremennyh usloviyah [Aspects of distance learning in modern conditions]. Mir nauki, kul'tury, obrazovaniya, 2020, no. 2 (81), pp. 355-358. (In Russ.)

3. Timoshenko D.S. Innovacionnye podhody $\mathrm{i}$ tekhnologii v turistskoj pedagogike [Innovative approaches and technologies in tourism pedagogy]. Vestnik Voron-

\section{Куролап Семен Александрович}

доктор географических наук, профессор, декан факультета географии, геоэкологии и туризма Воронежского государственного университета, г. Воронеж, Российская Федерация, ORCID: https://orcid.org/0000-0002-6169-8014, e-mail: skurolap@mail.ru ezhskogo gosudarstvennogo universiteta. Seria Geografiya. Geoekologiya, 2020, no. 1, pp. 115-123. (In Russ.) DOI: https://doi.org/10.17308/geo.2020.1/2669

4. Fedotov V. I., Kurolap S. A. Sovremennaya model' universitetskogo ekologicheskogo obrazovaniya [The modern model of higher environmental education]. Vestnik Voronezhskogo gosudarstvennogo universiteta. Seriya Problemy vysshego obrazovaniya, 2017, no. 3, pp. 14-18. (In Russ.)

Conflict of interest: The author declares no information of obvious and potential conflicts of interest related to the publication of this article.

Received: 02.11.2020 Accepted: 20.11.2020

Semen A. Kurolap

Dr. Sci. (Geogr.), Professor, Dean of the Faculty of Geography, Geoecology and Tourism Voronezh State University, Voronezh, Russian Federation, ORCID: https://orcid.org/0000-0002-6169-8014, e-mail: skurolap@mail.ru 